\title{
A Cost Analysis of Haemodialysis and Peritoneal Dialysis for the Management of End-Stage Renal Failure At an Academic Hospital in Pretoria, South Africa
}

\author{
Letlhogonolo Makhele $^{1} \cdot$ Moliehi Matlala $^{1} \cdot$ Mncengeli Sibanda $^{1} \cdot$ Antony P. Martin ${ }^{2,3} \cdot$ Brian Godman $^{1,2,4,5}$ (i)
}

Published online: 13 March 2019

(c) The Author(s) 2019, corrected publication 2019

\begin{abstract}
Background Haemodialysis (HD) and peritoneal dialysis (PD) are commonly used treatments for the management of patients with end-stage renal disease (ESRD). The costs of managing these patients have grown in recent years with increasing rates of non-communicable diseases, which will adversely impact on national health budgets unless addressed. Currently, there is limited knowledge of the costs of ESRD within the public healthcare system in South Africa.

Objective The aim of this study was to examine the direct costs of HD and PD in South Africa from a healthcare provider's perspective.

Methods A prospective, observational study was undertaken at a leading public hospital in South Africa. A micro-costing approach was applied to estimate healthcare costs using 46 adult patients with ESRD who had been receiving HD and PD for at least 3 months.

Results The highest proportion of patients (35\%) were aged 40-50 years. Patients aged 29-39 years were mostly on HD (28\% vs. $21 \%$ on PD) while those aged $51-59$ years mostly used PD ( $29 \%$ vs. $16 \%$ on HD). The average age of patients on HD and PD were 41 and 42 years, respectively. Fixed costs were the principal cost driver for $\mathrm{HD}(\$ 16,231.45)$ while variable costs were the principal cost driver for PD (US\$20,488.79). The annual cost of HD per patient (US\$31,993.12) was higher than PD (US\$25,282.00 per patient), even though the difference was not statistically significant ( $p=0.816$ ).

Conclusion HD costs more than PD from the provider's perspective. These cost estimates may be useful for carrying out future cost-effectiveness and cost-utility analyses in South Africa.
\end{abstract}

\section{Key Points for Decision Makers}

This is the first study in South Africa that compares the cost of different types of dialysis in the public healthcare system, with the study highlighting the biggest cost drivers for haemodialysis (HD) and peritoneal dialysis (PD).

The findings demonstrate that HD is more expensive than PD from a provider's perspective in South Africa.

Costs estimates found in this study can be used to inform future economic analyses and policies in combination with additional clinical and epidemiological studies to improve resource allocation for patients with kidney disease within a universal healthcare system.

Brian Godman

Brian.Godman@strath.ac.uk; Brian.Godman@ki.se

Extended author information available on the last page of the article

\section{Introduction}

The number of patients with chronic kidney disease (CKD) is increasing worldwide, with CKD now seen as a global epidemic enhanced by increasing rates of diabetes and hypertension [1-3]. The World Health Organization (WHO) estimated that there were 220 million people globally with CKD in 2012 [1]. This is a concern as it is believed currently only a few countries are able to fully meet the medical needs of these patients [4]. This situation will get worse unless this is addressed as a result of increasing rates of hypertension and diabetes mellitus, especially in lower and middle-income countries (LMICs), which includes countries in sub-Sahara Africa [5-8]. In 2013, the incidence of kidney disease was estimated at $10 \%$ in Africa and 8-16\% globally [9], although others have suggested the prevalence of CKD in sub-Sahara Africa is 13.9\% [10]. As a result of increases in CKD, deaths due to CKD increased by 67\% from 1999 to 2006 in South Africa alone [11]. Deaths due to CKD are expected to rise further in South Africa with rising rates of obesity and 
hypertension [6, 12]. It is estimated that by $2030>70 \%$ of patients worldwide with end-stage renal disease (ESRD) will be in developing countries unless key issues and concerns are addressed [13].

Chronic kidney disease (CKD) is defined as kidney damage or glomerular filtration rate (GFR) of $<60 \mathrm{~mL} / 1.73 \mathrm{~m}$ for 3 months or more, irrespective of the cause [14]. When the gradual loss of kidney function reaches an advanced state of GFR $<15 \mathrm{~mL} / 1.73 \mathrm{~m}$, this is known as CKD stage 5 or ESRD $[15,16]$.

ESRD contributes significantly to morbidity and mortality, decreasing life expectancy, whilst its management consumes an appreciable proportion of healthcare resources across countries including developing countries [13, 17-20]. It is estimated that up to $6 \%$ of the annual healthcare budget is spent on patients with ESRD in developed countries [20]. The optimal management of ESRD requires renal replacement therapy in the form of either dialysis or renal transplantation [9]. In the context of constrained budgets and rising patient demand for renal transplantation, many countries resort to dialysis as the initial preferred option for the management of ESRD [21].

As a result, dialysis programmes have shown an annual growth of between $6 \%$ and $12 \%$ over the past 20 years in developing countries [22]; however, growth rates are lower in Europe [23] and the US [24]. In view of the cost implications, only $4.5 \%$ of the world's dialysis population are currently in Africa, which is far lower than the envisaged population actually requiring dialysis in developing countries [25]. This is concerning given the high prevalence of non-communicable diseases (NCDs) such as hypertension and diabetes in Africa [5, 7, 26-29], which has been exacerbated by increasing urbanisation and the adoption of modern lifestyles [30, 31].

Due to an increase in the prevalence and financial burden of ESRD, a number of countries have undertaken studies to determine the cost of renal transplantation as well as haemodialysis (HD) and peritoneal dialysis (PD) to inform future policies [13, 20, 21, 25, 32]. However, these studies have drawn different conclusions, primarily due to the economic differences between high-, middle- and low-income countries [25, 33]. For example, in a single-centre study undertaken in Sudan, it was found that HD was less expensive when compared with renal transplantation, while the opposite was found in the United Kingdom and Mexico. However, the same study found that HD was more expensive when compared with renal transplantation in India [34]. A systematic review by Liu et al. involving 24 published papers found that PD is cost saving compared with in-centre HD therapy in most developed countries and some of the studied developing countries [35]. The disparities in the cost of HD and PD between high-income countries and LMICs might be attributed to a number of factors including lower wage rates among healthcare workers in low-income countries, which may result in lower costs of HD when compared with PD [33]. PD will generally also cost less in countries that have capacity for local manufacture of materials used in PD as well as in countries with a higher prevalence of patients undergoing PD owing to economies of scale [33]. This mix of factors will have an impact on overall dialysis costs in each country. Although PD is typically less expensive compared with HD in many parts of the world [20,35], the choice of dialysis modality may be influenced by other factors such as patient-population considerations, financial reimbursement, and incentives $[33,36]$.

In South Africa, life expectancy has increased significantly since the universal roll-out of antiretroviral therapy for the management of HIV, which was previously associated with high mortality [37-39]. This has resulted in an increasing proportion of ageing citizens and a concurrent increase in NCDs [40, 41]. In South Africa, only a minority of the population currently has medical insurance, with over $80 \%$ of the population relying on the public sector for health services [39]. There is a commitment though by the South African government to change this by providing universal health care through the National Health Insurance (NHI) scheme. This will benefit all patients in the future.

South Africa had approximately 260 centres for dialysis and renal transplant in 2015; however, close to $90 \%$ of these were privately owned [42]. As a result, kidney transplant rates remain low in South Africa and patients are forced to endure long periods of dialysis while waiting for a transplant [10]. In the South African private medical sector, patients are more likely to be managed by automated HD. Conversely, patients in the public sector are more likely to be managed using PD due to the limited number of treatment centres [42]. In addition, dialysis in the public sector is reserved for patients who are eligible to receive a kidney transplant [10]. The management of CKD is further constrained by the fact that South Africa currently has only 2.1 nephrologists per million population compared with, for instance, 16 nephrologists per million population in the USA [43, 44].

The increased burden of NCDs in South Africa, including patients with ESRD, has the potential to adversely impact health budgets and the allocation of scarce healthcare resources within the NHI scheme [39, 45, 46]. As such, the associated costs must be carefully managed. In view of this, the costs involved with treating chronic diseases such as CKD in the South African setting must be better understood.

Consequently, the objective of this study was to provide primary data on the cost of managing patients on either PD or HD in the public healthcare system in South Africa to inform economic evaluations as well as future health planning around patients with CKD in South Africa. 


\section{Methods}

\subsection{Study Site and Population}

The study was conducted in the renal unit at Dr George Mukhari Academic Hospital (DGMAH), located in the north of Pretoria. DGMAH was chosen for this study as it is one of the leading academic public hospitals in South Africa. The renal unit has a capacity of 22 beds, which comprises 20 beds for inpatients and two beds for outpatients. At the time of the study, the hospital had two groups of patients receiving HD treatment three times a week on alternate days and data was collected daily from the patient files to assess both groups. Patients on PD received monthly supplies; consequently, data from this group of patients was collected monthly. According to the South African Renal Registry 2015 annual report, the number of patients in South Africa currently on HD is 7529 and on PD is 1440 [42].

\subsection{Framework and Study Design}

This was a prospective observational study that assessed two cohorts (patients on either PD or HD). Data were collected from patient files over a period of 12 weeks (June 2017 to August 2017) using a developed data collection instrument. The instrument was piloted in the hospital before use in the main study. All adult patients undergoing chronic HD and PD at the DGMAH renal unit for at least 3 months were included in the study. Patient file numbers were used to ensure anonymity and maintain confidentiality of patientlevel data. A micro-costing approach was implemented to estimate the direct enumeration and costing of every item used for each individual patient.

\subsection{Cost Data Identification, Collection and Calculation}

The perspective of this study was that of a healthcare provider, and the costs were calculated based on the provider's expenditures. The costs were distinguished as initiation and maintenance costs for dialysis treatment. The initiation costs included the creation of a fistula for access and other processes that are necessary to prepare the patient for this lifelong treatment. Maintenance costs included all the costs incurred during the treatment sessions.

Costs were further differentiated between fixed, semivariable or variable costs. Costs that did not change over the short term were described as fixed costs and included the cost of the dialysis machine and maintenance. Non-medical fixed costs such as computers and beds were not included. Variable costs included electricity usage, laboratory tests, all materials and medicines that could be assigned directly to one HD session (see Box 1 in Appendix). For PD, variable costs included medicines, dialysis solutions, laboratory tests and other consumables given to the patients every month (Box 1). Box 1 also contains other costs that were not included such as administrative costs, hotel or indirect costs, as well as informal home care costs, water and electricity costs for PD patients.

Patients' files were reviewed and demographic data, comorbidities, as well as any relevant information that allowed for the determination of fixed, semi-variable and variable costs including medication costs of the two treatment modalities were obtained from the facility. Medicines are typically procured by their generic name (INN-international non-proprietary name), with prices obtained from the South African National Department of Health tender single exit price list. The medicines were provided free of charge by the provider hospital.

Water consumption of a single dialysis procedure was multiplied by the price per litre (including sewage charges and value added tax) to obtain the cost according to the local municipality charges. In order to obtain the cost of electricity usage per month, all electrical appliances at the unit, watts consumed by each appliance, duration of usage per day, and the number of days the unit operated per month, were combined. The total electricity consumption was calculated according to the standard local electricity provider's levies. The cost of sterilisation per month was determined by multiplying the total number of sterilised packs by the unit price of each pack. Laboratory tests were calculated by adding the costs together for all tests carried out on each patient. For all other medical consumables, such as sterile gloves, the prices were again obtained from the South African National Department of Health tender single exit price list.

Costs that increase stepwise (in a series of distinct stages) were described as semi-variable costs. Semi-variable costs, including staff wages (Box 1), were obtained from DGMAH's human resource department. In the case of dialysis machines, the depreciation per dialysis machine was calculated based on 8 years of functionality, which is typically their life span in the unit.

PD was provided at home; consequently, costs including informal home care costs, water and electricity costs could not be calculated using our methodology and were not included (Box 1).

\subsection{Data Analysis}

Data were entered in Microsoft Excel ${ }^{\circledR}$, checked for accuracy and cleaned prior to analysis. The data were then transferred to SPSS ${ }^{\circledR}$ full version 24 by the statistician and analysed descriptively by the authors. All costs were expressed in South African currency (Rands) then converted to United States Dollars (US\$) using the exchange rate 
(US $\$ 1.00=\mathrm{R} 13.038$ ) at the time of study [47]. All data for patient demographics (gender, age and race) and comorbidities were summarised as means frequency and percentages.

\subsection{Ethics Approval and Consent to Participate}

Ethical clearance was obtained from the Sefako Makgatho University Research Ethics Committee (SMUREC/P/68/2017) before the commencement of the study. In order to protect the identity of patients, a unique study number was assigned to each patient. Only the study number was used as a reference in the database. The names and identity numbers of the patients were excluded on the data collection forms. All data extraction forms were anonymised so that only the researcher had access to the patient information. Written permission was obtained from the CEO of DGMAH prior to the commencement of the study.

\section{Results}

\subsection{Patient Demographics}

Figure 1 shows that the highest proportion of the 46 patients studied were aged 40-50 years. All were Black South African patients. Patients aged 29-39 years were mostly on HD, and those aged $51-59$ years were mostly used PD. The mean average age of patients was 41 and 42 years for HD and $\mathrm{PD}$, respectively, with a standard deviation of 8.4 and 11.71 , respectively. In those receiving $\mathrm{HD}, 46 \%$ were females and 54\% males. There was an even split (50:50) for PD.

The majority of patients (HD 81\%; PD 57\%) had hypertension as a comorbidity followed by HIV (HD 19\%; PD $21 \%)$. Heart failure was also common in PD patients (36\%).
Table 1 Comorbidities in patients on HD and PD

\begin{tabular}{lll}
\hline & HD $(n=32)(\%)$ & PD $(n=14)(\%)$ \\
\hline Hypertension & 81 & 57 \\
HIV & 19 & 21 \\
Heart failure & 3 & 36 \\
Other & 13 & 0 \\
\hline
\end{tabular}

$N B$ Patients can have more than one co-morbidity, $H D$ Haemodialysis, $P D$ peritoneal dialysis

Other comorbidities in patients receiving HD (13\%) included diabetes (three patients) and epilepsy (one patient) (Table 1).

\subsection{Treatment Costs}

This section presents the costs associated for both treatment modalities. This includes the semi-variable costs broken down into maintenance and access costs, the variable costs for both modalities, the fixed costs (medical and non-medical) and the costs of medicines, including the most costly medicines for both treatment modalities. All medicine costs were combined without looking specifically at one class, such as antibiotics, given the high rate of HIV among the studied population (Table 1). The costs of equipment for HD are included. Finally, the annual cost comparison between $\mathrm{HD}$ and PD is presented. Table 2 presents the semi-variable costs of both modalities. Staff salaries per month were similar for HD and PD.

Table 3 contains details of the variable costs for HD. Laboratory tests costs were the main contributors (37.1\%), while haemo acid $(12.31 \%)$ and bicarbonate $(11.87 \%)$ also contributed to the variable costs. Syringes, disposable masks and disposable plastic aprons contributed the least to the variable costs.
Fig. 1 Age distribution for HD and PD

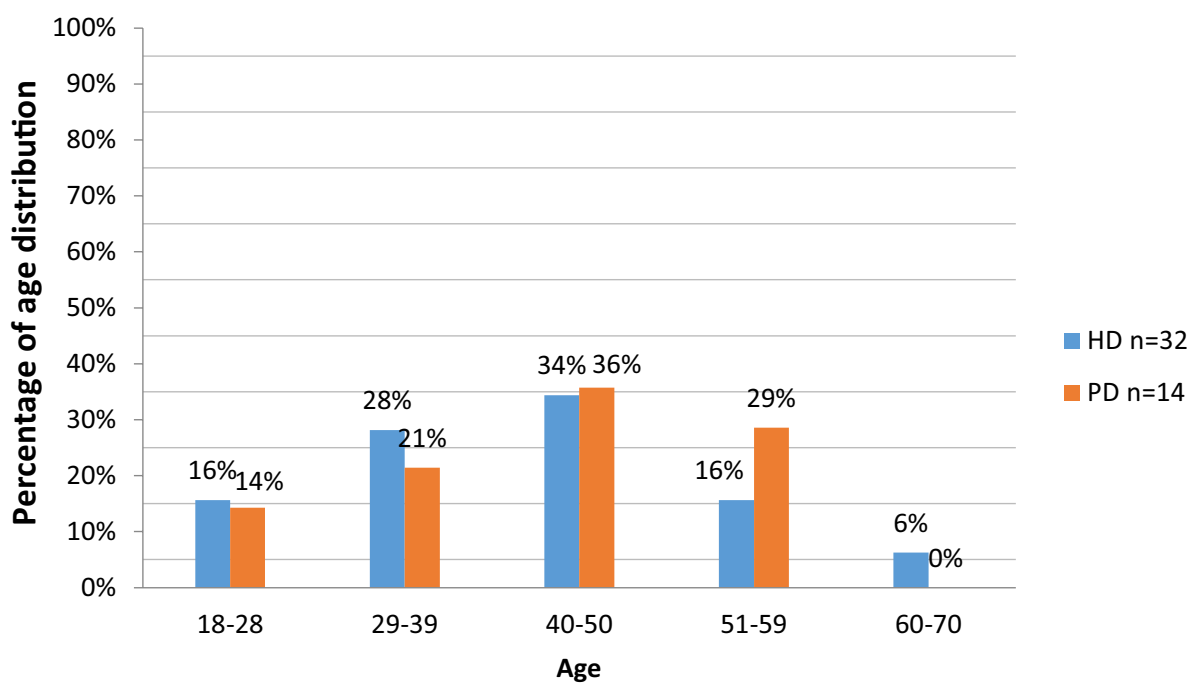


Table 2 Semi-variable costs per month per patient

\begin{tabular}{|c|c|c|c|c|c|c|c|c|}
\hline & \multicolumn{4}{|c|}{ Haemodialysis } & \multicolumn{4}{|c|}{ Peritoneal dialysis } \\
\hline & $\begin{array}{l}\text { Cost for } \\
\text { maintenance } \\
\text { (R) }\end{array}$ & $\begin{array}{l}\text { Cost for access } \\
\text { (R) }\end{array}$ & Cost (US\$) & $\begin{array}{l}\text { Contribution to } \\
\text { total semi-vari- } \\
\text { able costs (\%) }\end{array}$ & $\begin{array}{l}\text { Cost for } \\
\text { maintenance } \\
(\mathrm{R})\end{array}$ & $\begin{array}{l}\text { Cost for access } \\
\text { (R) }\end{array}$ & Cost (US\$) & $\begin{array}{l}\text { Contribution to } \\
\text { total semi-vari- } \\
\text { able costs }(\%)\end{array}$ \\
\hline $\begin{array}{l}\text { Nursing assis- } \\
\text { tant }\end{array}$ & 924.00 & 0.00 & 70.68 & 10.49 & 0.00 & 0.00 & 0.00 & 0.00 \\
\hline Dialysis nurse & $2,700.00$ & 0.00 & 206.52 & 30.67 & 0.00 & 0.00 & 0.00 & 0.00 \\
\hline Registrar & $4,200.00$ & 0.00 & 321.25 & 47.70 & 350.00 & 0.00 & 26.77 & 35.30 \\
\hline Nurse & 0.00 & 28.25 & 2.16 & 0.32 & 28.25 & 28.50 & 4.34 & 5.72 \\
\hline Social worker & 243.48 & 20.29 & 20.18 & 3.00 & 20.29 & 20.29 & 3.10 & 4.09 \\
\hline Phlebotomist & 157.44 & 0.00 & 12.04 & 1.79 & 13.12 & 0.00 & 1.00 & 1.32 \\
\hline $\begin{array}{l}\text { Anaesthesiology } \\
\text { per hour }\end{array}$ & 0.00 & 450.00 & 34.42 & 5.11 & 0.00 & 450.00 & 34.42 & 45.39 \\
\hline Dieticians & 0.00 & 81.00 & 6.20 & 0.92 & 0.00 & 81.00 & 6.20 & 8.17 \\
\hline
\end{tabular}

Currency conversion rate: 1 US Dollar $($ US $\$)=13.07380$ Rand $(\mathrm{R})$

Table 3 Variable costs of haemodialysis per year per patient

\begin{tabular}{lcccc}
\hline Variable & $\begin{array}{l}\text { Cost for mainte- } \\
\text { nance (US\$) }\end{array}$ & $\begin{array}{l}\text { Cost for } \\
\text { access (US\$) }\end{array}$ & Total cost (US\$) & $\begin{array}{l}\text { Contribution to total } \\
\text { variable costs (\%) }\end{array}$ \\
\hline Laundry & 81.74 & 0.0 & 81.74 & 1.10 \\
Laboratory test & 2470.52 & 284.49 & 2755.01 & 37.10 \\
Haemo acid & 914.19 & 0.0 & 914.19 & 12.31 \\
Bicarbonate & 881.15 & 0.0 & 881.15 & 11.87 \\
Bleach & 568.23 & 0.0 & 568.23 & 7.65 \\
Bloodlines & 517.68 & 0.0 & 517.68 & 6.97 \\
Clamp & 461.50 & 3.20 & 464.70 & 6.26 \\
Catheter & 0.0 & 197.76 & 197.76 & 2.66 \\
Electricity cost & 159.71 & 0.0 & 159.71 & 2.15 \\
Normal saline 500 mL & 154.20 & 0.0 & 154.20 & 2.08 \\
Water cost & 137.35 & 0.0 & 137.35 & 1.85 \\
0.94 Heparin 5000 IU & 115.43 & 0.83 & 116.26 & 1.57 \\
Sterile gloves & 104.86 & 0.73 & 105.59 & 1.42 \\
Adhesive wound plaster & 89.77 & 0.0 & 89.77 & 1.21 \\
IV giving set & 73.47 & 0.0 & 73.47 & 0.99 \\
Ultrasound & 0.0 & 68.84 & 68.84 & 0.93 \\
Needles & 60.14 & 0.42 & 60.56 & 0.82 \\
Syringe 5 cm & 35.75 & 0.0 & 40.75 & 0.55 \\
Iron lab test & 16.64 & 0.0 & 16.64 & 0.22 \\
Disposable mask & 11.79 & 0.0 & 11.79 & 0.16 \\
Alcohol swabs & 10.24 & 0.0 & 10.24 & 0.14 \\
\hline
\end{tabular}

Currency conversion rate: 1 US Dollar (US\$) $=13.07380$ Rand $(\mathrm{R})$
Table 4 summarises the variable costs for PD. Peritoneal dialysis solutions, namely Dianeal $1.5^{\circledR}$ and Dianeal $2.5^{\circledR}$ (US\$392.36 each), contributed the most when compared with the total variable cost of PD. The contribution of laboratory tests to overall variable costs was also high (25.9\%), with gloves, needles and lignocaine contributing the least to the total cost of PD.
Tables 3 and 4 also present a detailed cost breakdown of variable costs, including one-off costs for fistula access for both modalities. Other variable costs that contributed to total costs included ultrasound for PD but not for HD (HD: US\$68.4; PD: US\$ 68.84) as well as haemo acid and bicarbonate (US\$914.19 and US\$881.15) for HD patients. 
Table 4 Variable costs of peritoneal dialysis per month per patient
Table 5 Fixed medical costs per year associated with dialysis machines

\begin{tabular}{|c|c|c|c|c|}
\hline Variable costs & $\begin{array}{l}\text { Cost for mainte- } \\
\text { nance (US\$) }\end{array}$ & $\begin{array}{l}\text { Cost for access } \\
\text { (US\$) }\end{array}$ & Total cost (US\$) & $\begin{array}{l}\text { Contribution to total } \\
\text { variable costs }(\%)\end{array}$ \\
\hline Laboratory test & 205.9 & 284.5 & 490.4 & 25.87 \\
\hline Dianeal $1.5 \mathrm{NC}^{\circledR}$ & 392.4 & 0 & 392.4 & 20.70 \\
\hline Dianeal $2.5 \mathrm{NC}^{\circledR}$ & 392.4 & 0 & 392.4 & 20.70 \\
\hline Mincap ${ }^{\circledR}$ & 205.9 & 0 & 205.9 & 10.86 \\
\hline Catheter & 0 & 197.8 & 197.8 & 10.43 \\
\hline K-Shield & 137.5 & 0 & 137.5 & 7.25 \\
\hline Ultrasound & 0 & 68.4 & 68.4 & 3.61 \\
\hline Iron lab test & 5.5 & 0 & 5.5 & 0.29 \\
\hline Clamp & 0 & 3.2 & 3.2 & 0.17 \\
\hline Heparin & 0 & 0.8 & 0.8 & 0.04 \\
\hline Gloves & 0 & 0.7 & 0.7 & 0.04 \\
\hline Needles & 0 & 0.4 & 0.4 & 0.02 \\
\hline Lignocaine & 0 & 0.2 & 0.2 & 0.01 \\
\hline
\end{tabular}

Currency conversion rate: 1 US Dollar $($ US $\$)=13.07380$ Rand $(\mathrm{R})$

\begin{tabular}{lccc}
\hline & Annual cost (R) & Annual cost (US\$) & $\begin{array}{l}\text { Proportion of } \\
\text { the total cost } \\
(\%)\end{array}$ \\
\hline Dialysis machine & $138,326.79$ & $10,580.46$ & 65.18 \\
Maintenance & $46,214.72$ & 3534.91 & 21.78 \\
Equipment depreciation & $27,665.40$ & 2116.08 & 13.04 \\
Total cost & $212,206.91$ & $16,231.45$ & 100.00 \\
\hline
\end{tabular}

Currency conversion rate: 1 US Dollar (US\$) $=13.07380$ Rand $(\mathrm{R})$

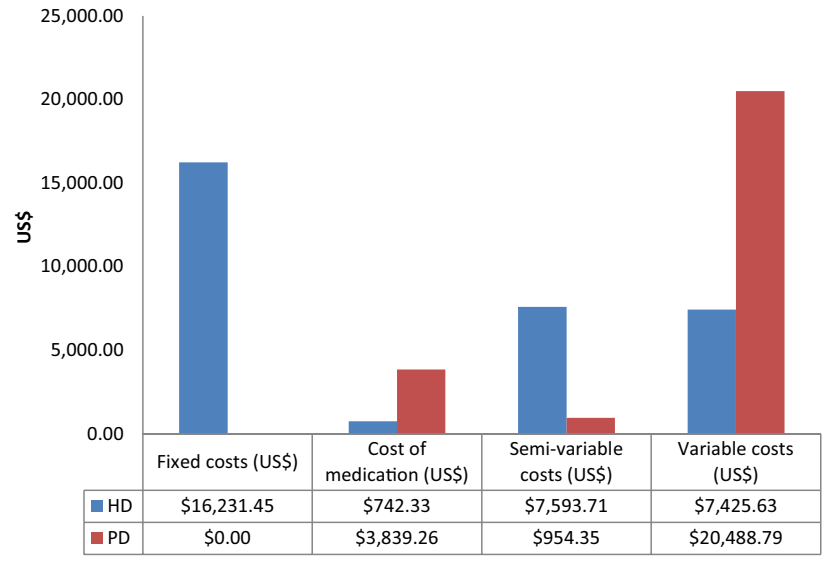

Fig. 2 Annual cost comparison between HD and PD

In public sector hospitals in South Africa including DGMAH, HD patients attend therapy sessions up to three times a week, with each session typically lasting up to $4 \mathrm{~h}$ [48]. This is reflected in the high variable costs for HD patients.
Table 6 Five most costly medicines for both HD and PD per month

\begin{tabular}{lcc}
\hline & Cost in Rands & Cost in U\$S \\
\hline Erythropoietin 4000 IU & 3848.20 & 294.34 \\
Furosemide 500 mg & 833.83 & 63.78 \\
Doxazosin & 301.50 & 23.06 \\
Lopinavir/ritonavir & 185.90 & 14.22 \\
Fixed-dose combination & 119.42 & 9.13 \\
\hline
\end{tabular}

Currency conversion rate: 1 US Dollar $(\mathrm{US} \$)=13.07380$ Rand $(\mathrm{R})$

Table 5 includes the direct medical fixed costs of HD, which includes dialysis machine purchase costs, 5-year maintenance service costs and equipment depreciation costs. These costs are reflected in Fig. 2.

\subsection{Cost of Medicines}

The average of seven medications per prescription for HD patients with an average cost of US\$61.84 was lower than that of PD patients at an average of nine medications per prescription costing an average of US $\$ 319.85$. Overall, the 
annual cost of medicines was US\$742.33 for HD patients and US\$3839.26 for PD patients (Fig. 2).

Table 6 highlights the five most costly medicines used for both modalities and their associated costs.

Figure 2 illustrates that the annual cost for treating PD patients (US\$25,282.39) was lower than that for treating HD patients (US\$31,993.12) although this was not statistically significant. Variable costs; PD: (US\$20,488.79) and direct costs HD(US\$16,231.45) were the biggest cost drivers.

\section{Discussion}

In this study, the majority of patients were on HD compared with PD, which was consistent with the recent South African Renal Registry Annual Report (HD: 71.2\%, PD: 14\%) [42] and the European Renal Association-European Dialysis Treatment Association Registry (ERA-EDT) 2015 (HD: 66\%, PD: 29\%) [49]. These findings are also consistent with Jain et al., who reported that $12.4 \%$ of dialysis patients in developing countries were now on PD; although there was substantial variation between countries [50]. The reasons for the differences could be largely based on socioeconomic factors such as access to sanitation [51]. There were also more males than females on treatment in our study, which reflected the general gender distribution of patients on dialysis in South Africa [42], Tanzania [13], Sudan [34], European countries [49] and the Cameroon [18].

The majority of patients in the study were also hypertensive, comparable to the US where $84 \%$ of patients with stage 4-5 renal failure had hypertension [24]. Hypertension can either be the cause of the renal failure or it develops as a complication due to renal failure, with heart failure a complication of advanced renal disease [52]. In the US, the prevalence of heart failure is $63 \%$ in patients with CKD, whereas the prevalence of heart failure in our study was lower for both modalities (HD: 3\%, PD: 36\%) [24]. The possible under-reporting of heart failure in our study may be due to the study's sole reliance on patients' files for information rather than a lack of diagnosis of heart failure; however, we cannot say this with certainty, and we will be looking at this further in future research projects.

HIV was the second most common comorbidity of renal failure in our study. This is expected since HIV is highly prevalent in South Africa, endorsing the need to look closely at this co-morbidity, especially among patients in sub-Sahara Africa [41]. Renal failure in HIV can either be caused by direct infection of the kidney or as a result of antiretroviral drugs [53, 54]. However, due to insufficient information in the patients' files, it is unclear whether the patients acquired renal disease before or after they were diagnosed with HIV. Diabetes mellitus is another leading cause of renal failure [1]. However, this study found only three patients who were on HD had diabetes mellitus as a comorbidity. This is perhaps not surprising as dialysis is not currently funded for these patients within the South African public healthcare systems, with a belief that scarce available resources are better spent preventing CKD in these patients in the first place with better management of their diabetes. Consequently, programmes to improve access to medicines and their use as part of chronic disease management programmes in patients with diabetes should help in this regard [39]. All patients in the renal unit received treatment for anaemia, which is not surprising as it is the most common complication of chronic renal failure.

Overall, patients on HD had more comorbidities than those on PD in our study, which is similar to the findings of Chang et al. [20]. It is important to manage these comorbidities appropriately, including encouraging adherence to prescribed medicines for NCDs, which is a concern in subSahara Africa as this poses a considerable financial burden to health systems [7, 29, 55-58]. For instance, the number of HD or PD sessions may increase per week if comorbidities are not managed adequately [59].

The average number of medicines per prescription was higher for PD patients (HD: 7; PD: 9). Similarly, the average cost per prescription was higher for PD versus HD patients, which was due mostly to the greater use of erythropoietin in the treatment of anaemia in PD patients, with erythropoietin dominating the medicine costs (Table 6). Medicines such as furosemide and doxazosin are used to treat the comorbidities of HD and PD patients. The higher prevalence of heart failure in PD patients may also have added to higher medicine costs (Fig. 2). This is similar to findings in the UK where erythropoietin was one of the main dialysis cost drivers [60]. This is because almost all patients on either HD or PD were prescribed medication to prevent anaemia. Having said this, at DGMAH there is limited use of erythropoietin among HD patients as they are closely monitored during their three sessions per week. At these sessions, the medical staff check for physical signs of anaemia as a routine checkup of dialysis and instigate appropriate prevention measures. This is not the case with PD treatment as it is home based.

The high cost of laboratory tests for both modalities (accounting for $37.1 \%$ of variable costs for HD patients and $25.9 \%$ for PD patients-Tables 3 and 4) could be down to the current regulations for chronic renal dialysis patients in South Africa [61]. These mandate a number of tests in the management of patients on dialysis including urea and electrolytes, a full metabolic profile, creatinine, full blood count plus platelets, ELISA, hepatitis A B and C and INR [61].

Overall, the direct cost of HD in our study was higher than the cost of PD from the provider's perspective. This was the case in the initiation and maintenance phases of both modalities. This is similar to the findings of Berger et al. [32], Mushi et al. [13] and Chang et al. [20]. This is perhaps 
not surprising with HD hospital-based and PD home-based. The major cost drivers of dialysis treatment per month for PD were the variable costs and for HD the fixed costs (Fig. 2). As a result, the annual cost of HD (US\$31,993.12) was higher than PD although this was not statistically significant $(p=0.816)$. Moosa et al. estimated the cost of dialysis at approximately US $\$ 15,297.8$ per patient per annum at a conversion rate of US\$1 to R13.0378, which is close but lower than our findings for PD patients at US\$25,282 per patient/per annum (Fig. 2), which is encouraging [16]. As mentioned, according to the South African Renal Registry 2015 annual report, the number of patients in South Africa on HD is 7529 and PD is 1440 [42]. Using the annual costs found in this study, it will cost US $\$ 240,876,200.48$ to treat all patients on HD and US $\$ 36,406,646.0$ for patients on PD. This is a concern given the current gross domestic product (GDP) (US\$349.42 billion) of South Africa [62] and the current medical need for all patients within the public healthcare system, including new patients with ESRD. The cost ratio of HD/PD (1.26) was also higher than seen in a study by Okpechi et al., where this was 0.58 [25]. However, Abu-Aisha and Elamin [63] found that PD was more expensive than HD in most Sub-Saharan countries as these countries did not have the financial capacity or infrastructure to locally manufacture PD solutions [25]. This has to be considered when reviewing resource use across different country settings.

Several assumptions were made in this study. For instance, when calculating staff costs for HD, it was assumed that each patient was seen by a physician for an hour per HD session and monitored over $4 \mathrm{~h}$ by the dialysis nurse. It was also assumed that the machine for HD was purchased on initiation; consequently, we did not include depreciation costs in the initiation costs for HD. However, the depreciation costs and maintenance costs were included in the monthly variable costs. In addition, because micro-costing requires prospective data collection, but in this case, data were collected retrospectively in some HD patients because the data collector could only research one patient at a time, complete micro-costing for HD patients was impossible. As mentioned, there was also no discounting of costs. We realise this must be factored into any new analysis alongside administrative costs, building costs, hotel and bed costs (Box 1) as well as indirect costs. In addition, as mentioned, informal home care costs, water and electricity costs were not included in PD costs (Box 1).

We are also aware that this study was carried out in only one public hospital in South Africa, albeit a major public hospital in South Africa, with a limited number of patients. Despite these limitations, we believe this study was able to provide primary data on the current costs for HD and PD in South Africa from a public provider's perspective. We also believe this data can be combined with data from epidemiological studies, clinical studies, and other sources of information, to provide a foundation to enable broader health economic analyses such as cost-effectiveness and cost-utility analysis of the different treatment modalities to treat patients with ESRD in South Africa. These combined studies can subsequently be used to guide future decision making and planning for these patients in South Africa. This could also include programme budgeting and marginal analysis (PBMA) of different approaches to the prevention and earlier identification of patients with renal disease to reduce future morbidity, mortality and costs [64-67].

\section{Conclusion}

The costs of HD are higher than PD from a hospital provider perspective in South Africa. This was mainly due to laboratory costs and dialysis solutions for treating patients with HD due to the high number of sessions (up to 12 a month), as well as purchasing and maintaining the dialysis equipment. These are considerations for the future as the Government in South Africa commits to providing universal healthcare for all patients through the NHI.

Acknowledgements This work was made possible due to the support rendered by Mr Katlego Mokgwabone (statistician), who helped with the statistical analysis of the data. The authors would like to further acknowledge Nurse S. Tau of the DGMAH renal unit who assisted with the data collection.

Compliance with Ethical Standards There was no informed consent as data was extracted from patient records. However, in order to protect the identity of patients, a unique study number was assigned to each patient (used as a reference in the database). The names and identity numbers of the patients were excluded on the data collection forms. There was no funding for this project and all authors (L. Makhele, M. Matlala, M. Sibanda, A.P. Martin and B. Godman) declare they have no conflicts of interests. The study was approved by the appropriate institutional ethics committee and has been performed in accordance with the ethical standards of the Declaration of Helsinki.

Data Availability Further data will be available on request.

Author Contributions LM, MM and MS developed the concept for the study. The data collection and initial analysis was undertaken by LM with further input from APM, MM and BBG. LM, MM and BBG drafted the initial manuscript with all authors subsequently contributing to further drafts. All authors approved the final manuscript.

Open Access This article is distributed under the terms of the Creative Commons Attribution-NonCommercial 4.0 International License (http://creativecommons.org/licenses/by-nc/4.0/), which permits any noncommercial use, distribution, and reproduction in any medium, provided you give appropriate credit to the original author(s) and the source, provide a link to the Creative Commons license, and indicate if changes were made. 


\section{Appendix}

Box 1 Key annual cost items for patients (US\$) including costs not included in the Tables

\section{Fixed costs (medical)}

- Dialysis machines including maintenance: US\$16,231.45 (including depreciation-Table 5)

- Bed costs (for 22 beds): US\$44,965.13

- RO system: US\$15,000.00

- Aqua machine: US\$10,171.49

- Vital monitors (2): US\$2,192.09

- ECG: US\$1,758.64

- Emergency trolley: US\$893.38

- Defibrillator: US\$397.61

- Drip stands (22): US\$395.31

- Dressing trolley (3): US\$217.00

\section{Fixed costs (non-medical)}

- Overhead Tables (22): US\$3,168.01

- Computer for the ward: US\$611.7

- Printer: US\$191.16

- Desk: US\$81.97

\section{Semi-variable costs (details in Table 2)}

- Nursing costs, phlebotomist costs

- Physicians including anaesthetists

- Social workers

- Dieticians

\section{Variable costs (details in Tables 3 and 4)}

- Laundry

- Costs of tests including laboratory costs and iron lab costs

- Haemo Acid, bicarbonate, normal saline, water and heparin costs

- Bleach

- Bloodlines

- Clamps, catheters, sterile gloves, disposable masks, alcohol swabs

- Electricity

- Adhesive wound plasters, IV giving set, needles and syringes

- Ultrasound
Costs not included in fixed costs (Table 5 and Fig. 2)

- Administrative costs

- Beds (cost of the beds)

- Building and hotel costs

- Reverse osmosis system

- Vital monitors

- ECG monitors

- Emergency trolleys

- Defibrillators

- Drip stands

- Dressing trolleys

- Overhead tables

- Computers, printers and desks in the unit

- Informal home care costs as well as water and electricity (PD patients)

\section{References}

1. Detournay B, Simon D, Guillausseau PJ, Joly D, Verges B, Attali $\mathrm{C}$, et al. Chronic kidney disease in type 2 diabetes patients in France: prevalence, influence of glycaemic control and implications for the pharmacological management of diabetes. Diabetes Metabol. 2012;38(2):102-12.

2. Stanton RC. Clinical challenges in diagnosis and management of diabetic kidney disease. Am J Kidney Dis. 2014;63(2 Suppl 2):S3-21.

3. Go AS, Chertow GM, Fan D, McCulloch CE, Hsu CY. Chronic kidney disease and the risks of death, cardiovascular events, and hospitalization. N Engl J Med. 2004;351(13):1296-305.

4. Arogundade FA, Barsoum RS. CKD prevention in Sub-Saharan Africa: a call for governmental, nongovernmental, and community support. Am J Kidney Dis. 2008;51(3):515-23.

5. Irazola VE, Gutierrez L, Bloomfield G, Carrillo-Larco RM, Dorairaj P, Gaziano T, et al. Hypertension prevalence, awareness, treatment, and control in selected LMIC communities: results From the NHLBI/UHG network of centers of excellence for chronic diseases. Global Heart. 2016;11(1):47-59.

6. Cois A, Day C. Obesity trends and risk factors in the South African adult population. BMC Obesity. 2015;2:42.

7. Nashilongo MM, Singu B, Kalemeera F, Mubita M, Naikaku E, Baker A, et al. Assessing adherence to antihypertensive therapy in primary health care in namibia: findings and implications. Cardiovasc Drugs Ther. 2017;31(5-6):565-78.

8. Rwegerera GM, Molefe-Baikai OJ, Masaka A, Shimwela M, Rivera YP, Oyewo TA, et al. Prevalence of chronic kidney disease using estimated glomerular filtration rate among diabetes patients attending a tertiary clinic in Botswana. Hospital Pract. 2018.

9. Jha V, Garcia-Garcia G, Iseki K, Li Z, Naicker S, Plattner B, et al. Chronic kidney disease: global dimension and perspectives. Lancet. 2013;382(9888):260-72.

10. Etheredge H, Fabian J. Challenges in Expanding Access to Dialysis in South Africa-Expensive Modalities, Cost Constraints and Human Rights. Healthcare. 2017;5(3).

11. Moosa MR, Van der Walt I, Naicker S, Meyers AM. Important causes of chronic kidney disease in South Africa. S Afr Med J. 2015;105(4):2681.

12. Rampamba EM, Meyer JC, Helberg E, Godman B. Knowledge of hypertension and its management among hypertensive patients on chronic medicines at primary health care public sector facilities in 
South Africa; findings and implications. Expert Rev Cardiovasc Therapy. 2017;15(8):639-47.

13. Mushi L, Krohn M, Flessa S. Cost of dialysis in Tanzania: evidence from the provider's perspective. Health Econ Rev. 2015;5(1):28.

14. Disease: Improving Global Outcomes (KDIGO) CKD-MBD Update Work Group, Kidney. KDIGO 2017 clinical practice guideline update for the diagnosis, evaluation, prevention, and treatment of Chronic Kidney Disease-Mineral and Bone Disorder (CKD-MBD). Kidney Int Suppl. 2017;7:1-59.

15. Katz I, Schneider H, Shezi Z, Mdleleni G, Gerntholtz T, Butler $\mathrm{O}$, et al. Managing type 2 diabetes in Soweto-The South African Chronic Disease Outreach Program experience. Primary Care Diabetes. 2009;3(3):157-64

16. Moosa MR, Meyers AM, Gottlich E, Naicker S. An effective approach to chronic kidney disease in South Africa. S Afr Med J. 2016;106(2):156-9.

17. Barsoum RS. Chronic kidney disease in the developing world. $\mathrm{N}$ Engl J Med. 2006;354(10):997-9.

18. Halle MP, Takongue C, Kengne AP, Kaze FF, Ngu KB. Epidemiological profile of patients with end stage renal disease in a referral hospital in Cameroon. BMC Nephrol. 2015;16:59.

19. Grassmann A, Gioberge S, Moeller S, Brown G. ESRD patients in 2004: global overview of patient numbers, treatment modalities and associated trends. Nephrol Dial Transplant. 2005;20(12):2587-93.

20. Chang YT, Hwang JS, Hung SY, Tsai MS, Wu JL, Sung JM, et al. Cost-effectiveness of hemodialysis and peritoneal dialysis: a national cohort study with 14 years follow-up and matched for comorbidities and propensity score. Sci Rep. 2016;6:30266.

21. Bavanandan S, Ahmad G, Teo AH, Chen L, Liu FX. Budget impact analysis of peritoneal dialysis versus conventional incenter hemodialysis in Malaysia. Value Health Regional Issues. 2016;9:8-14.

22. Couser WG, Remuzzi G, Mendis S, Tonelli M. The contribution of chronic kidney disease to the global burden of major noncommunicable diseases. Kidney Int. 2011;80(12):1258-70.

23. Treharne C, Liu FX, Arici M, Crowe L, Farooqui U. Peritoneal dialysis and in-centre haemodialysis: a cost-utility analysis from a UK payer perspective. Appl Health Econ Health Policy. 2014;12(4):409-20.

24. Collins AJ, Foley RN, Chavers B, Gilbertson D, Herzog C, Ishani A, et al. US renal data system 2013 annual data report. Am J Kidney Dis. 2014;63(1 Suppl):A7.

25. Okpechi IG, Rayner BL, Swanepoel CR. Peritoneal dialysis in Cape Town, South Africa. Perit Dial Int. 2012;32(3):254-60.

26. Ataklte F, Erqou S, Kaptoge S, Taye B, Echouffo-Tcheugui JB, Kengne AP. Burden of undiagnosed hypertension in sub-saharan Africa: a systematic review and meta-analysis. Hypertension. 2015;65(2):291-8.

27. Commodore-Mensah Y, Samuel LJ, Dennison-Himmelfarb CR, Agyemang C. Hypertension and overweight/obesity in Ghanaians and Nigerians living in West Africa and industrialized countries: a systematic review. J Hypertens. 2014;32(3):464-72.

28. Onyenekwu CP, Dada AO, Babatunde OT. The prevalence of metabolic syndrome and its components among overweight and obese Nigerian adolescents and young adults. Nigerian J Clin Pract. 2017;20(6):670-6.

29. Rwegerera GM, Moshomo T, Gaenamong M, Oyewo TA, Gollakota S, Mhimbira FA, et al. Antidiabetic Medication Adherence and Associated Factors among Patients in Botswana; implications for the future. Alexan J Med. 2018;54(2):103-9.

30. Adeniyi AB, Laurence CE, Volmink JA, Davids MR. Prevalence of chronic kidney disease and association with cardiovascular risk factors among teachers in Cape Town, South Africa. Clin Kidney J. 2017;10(3):363-9.
31. World Health Organisation. WHO African Region Ministerial Consultation on Noncommunicable Diseases. Brazzaville, Congo. Hosted in Brazzaville by the WHO/AFRO 2011. Available at URL: http://www.who.int/nmh/events/2011/africa_ncds_backg round_paper.pdf.

32. Berger A, Edelsberg J, Inglese GW, Bhattacharyya SK, Oster G. Cost comparison of peritoneal dialysis versus hemodialysis in end-stage renal disease. Am J Manag Care. 2009;15(8):509-18.

33. Klarenbach SW, Tonelli M, Chui B, Manns BJ. Economic evaluation of dialysis therapies. Nat Rev Nephrol. 2014;10(11):644-52.

34. Elsharif ME, Elsharif EG, Gadour WH. Costs of hemodialysis and kidney transplantation in Sudan: a single center experience. Iran J Kidney Dis. 2010;4(4):282-4.

35. Liu FX, Quock TP, Burkart J, Noe LL, Inglese G. Economic evaluations of peritoneal dialysis and hemodialysis: 2004-2012. F1000Research. 2013. 2-273: 1-13. Available at URL: https:// f1000researchdata.s3.amazonaws.com/manuscripts/3142/bfe $5 \mathrm{f}$ 231-05b4-4916-aee8-234c890e557d_2914\%20-\%20frank\%20 liu.pdf?doi=10.12688/f1000research.2-273.v1.

36. Clement Nee Shrive FM, Ghali WA, Donaldson C, Manns BJ. The impact of using different costing methods on the results of an economic evaluation of cardiac care: microcosting vs grosscosting approaches. Health Econ. 2009;18(4):377-88.

37. Nair Y, Campbell C. Building partnerships to support communityled HIV/AIDS management: a case study from rural South Africa. Afr J AIDS Res. 2008;7.

38. NDOH. National Department of Health Republic of South Africa. Adherence Guidelines for HIV, TB and NCDs. Policy and service delivery guidelines to care, adherence to treatment and retention in care. February 2016. Available at URL: https://www.nacosa.org. $\mathrm{za} / \mathrm{wp}$-content/uploads/2016/11/Integrated-Adherence-Guidelines -NDOH.pdf.

39. Meyer JC, Schellack N, Stokes J, Lancaster R, Zeeman H, Defty $\mathrm{D}$, et al. Ongoing initiatives to improve the quality and efficiency of medicine use within the public healthcare system in South Africa; A Preliminary Study. Front Pharmacol. 2017;8:751.

40. Bor J, Herbst AJ, Newell ML, Barnighausen T. Increases in adult life expectancy in rural South Africa: valuing the scale-up of HIV treatment. Science. 2013;339(6122):961-5.

41. Statistics South Africa. Mid-year population estimates 2017. Available from URL: http://www.statssa.gov.za/publications/ P0302/P03022017.pdf.

42. Davids MR, Marais N, Jacobs JC. South African Renal Registry Annual Report 2015. Afr J Nephrol. 2017; 20(1): 201-13. Available at URL: file:///C:/Users/mail/Downloads/2583-8331-1-SM. pdf.

43. Kilonzo KG, Jones ESW, Okpechi IG, Wearne N, Barday Z, Swanepoel CR, et al. Disparities in dialysis allocation: an audit from the new South Africa. PLoS One. 2017;12(4):e0176041.

44. Swanepoel CR, Wearne N, Okpechi IG. Nephrology in Africa-not yet uhuru. Nat Rev Nephrol. 2013;9(10):610-22.

45. Passchier RV. Exploring the barriers to implementing National Health Insurance in South Africa: the people's perspective. S Afr Med J. 2017;107(10):836-8.

46. Gray A, Vawda Y. Health Policy and Legislation. SAHR 2016; 3-15. Available at URL: http://www.hst.org.za/publications/South $\% 20$ African $\% 20$ Health $\% 20$ Reviews $/ 1 \% 20$ Health $\% 20$ Policy $\% 20$ and\%20Legislation.pdf.

47. PoundSterling Live. Historical Rates for the USD/ZAR currency conversion on 13 September 2017 (13/09/2017). Available at URL: https://www.poundsterlinglive.com/best-exchange-rates/ us-dollar-to-south-african-rand-exchange-rate-on-2017-09-13.

48. National Kidney Foundation of South Africa. Some common kidney diseases. 2017. Available at URL: http://www.nkf.org.za/.

49. Kramer A, Pippias M, Noordzij M, Stel VS, Afentakis N, Ambuhl PM, et al. The European Renal Association-European Dialysis 
and Transplant Association (ERA-EDTA) Registry Annual Report 2015: a summary. Clin Kidney J. 2018;11(1):108-22.

50. Jain AK, Blake P, Cordy P, Garg AX. Global trends in rates of peritoneal dialysis. J Am Soc Nephrol. 2012;23(3):533-44.

51. Karopadi AN, Mason G, Rettore E, Ronco C. Cost of peritoneal dialysis and haemodialysis across the world. Nephrol Dial Transplant. 2013;28(10):2553-69.

52. Jande M, Katabalo DM, Sravanam P, Marwa C, Madlan B, Burger J, et al. (2017) Patient-related beliefs and adherence toward their medications among the adult hypertensive outpatients in Tanzania. J Comp Eff Res. https://doi.org/10.2217/cer-2016-0060.

53. Kalyesubula R, Perazella MA. Nephrotoxicity of HAART. AIDS Res Treat. 2011;2011:562790.

54. Kalemeera F, Mbango C, Mubita M, Naikaku E, Gaida R, Godman B. Effect of changing from first- to second-line antiretroviral therapy on renal function: a retrospective study based on data from a single health facility in Namibia. Expert Rev Anti-Infect Therapy. 2016;14(8):777-83.

55. Rampamba EM, Meyer JC, Godman B, Kurdi A, Helberg E. Evaluation of antihypertensive adherence and its determinants at primary healthcare facilities in rural South Africa. J Compar Effect Res 2018;7(7):661-72.

56. Corrao G, Parodi A, Nicotra F, Zambon A, Merlino L, Cesana G, et al. Better compliance to antihypertensive medications reduces cardiovascular risk. J Hypertens. 2011;29(3):610-8.

57. Herttua K, Martikainen P, Batty GD, Kivimäki M. Poor adherence to statin and antihypertensive therapies as risk factors for fatal stroke. J Am Coll Cardiol. 2016;67(13):1507-15.

58. Nielsen JO, Shrestha AD, Neupane D, Kallestrup P. Non-adherence to anti-hypertensive medication in low- and middle-income countries: a systematic review and meta-analysis of 92443 subjects. J Hum Hypertens. 2017;31(1):14-21.
59. Teerawattananon Y, Mugford M, Tangcharoensathien V. Economic evaluation of palliative management versus peritoneal dialysis and hemodialysis for end-stage renal disease: evidence for coverage decisions in Thailand. Value Health. 2007;10(1):61-72.

60. Baboolal K, McEwan P, Sondhi S, Spiewanowski P, Wechowski J, Wilson $\mathrm{K}$. The cost of renal dialysis in a UK setting-a multicentre study. Nephrol Dial Transplant. 2008;23(6):1982-9.

61. South African Renal Society. Guideline for the optimal care of patients on chronic dialysis in South Africa. 2015. Available at URL: http://sa-renalsociety.org/wp-content/uploads/2018/03/ SARS-Guideline1_ChronicDialysis-Adults_2015d.pdf.

62. Trading Economics. South Africa GDP in 2017. Availble at URL: https://tradingeconomics.com/south-africa/gdp.

63. Abu-Aisha H, Elamin S. Peritoneal dialysis in Africa. Periton Dial Int. 2010;30(1):23-8.

64. Mitton C, Donaldson C. Health care priority setting: principles, practice and challenges. Cost Eff Resour Alloc. 2004;2:3.

65. Edwards RT, Charles JM, Thomas S, Bishop J, Cohen D, Groves $\mathrm{S}$, et al. A national programme budgeting and marginal analysis (PBMA) of health improvement spending across Wales: disinvestment and reinvestment across the life course. BMC Public Health. 2014;14:837.

66. Hunter RM, Fulop NJ, Boaden RJ, McKevitt C, Perry C, Ramsay AIG, et al. The potential role of cost-utility analysis in the decision to implement major system change in acute stroke services in metropolitan areas in England. Health Res Policy Syst. 2018;16(1):23.

67. Grocott R. Applying programme budgeting marginal analysis in the health sector: 12 years of experience. Expert Rev Pharmacoecon Outcomes Res. 2009;9(2):181-7.

\section{Affiliations}

\section{Letlhogonolo Makhele $^{1} \cdot$ Moliehi Matlala $^{1} \cdot$ Mncengeli Sibanda $^{1} \cdot$ Antony P. Martin $^{2,3} \cdot$ Brian Godman $^{1,2,4,5}$}

Letlhogonolo Makhele

makhele.nolo@gmail.com

Moliehi Matlala

moliehi.matlala@smu.ac.za

Mncengeli Sibanda

mncengelis@gmail.com

Antony P. Martin

a.p.martin@liverpool.ac.uk;

antony.martin@hcdeconomics.com

1 Department of Public Health and Pharmacy Management, School of Pharmacy, Sefako Makgatho Health Sciences University, Pretoria, South Africa
2 Health Economics Centre, University of Liverpool Management School, Chatham Street, Liverpool, UK

3 HCD Economics, The Innovation Centre, Daresbury WA4 4FS, UK

4 Strathclyde Institute of Pharmacy and Biomedical Sciences, University of Strathclyde, Glasgow G4 ORE, UK

5 Division of Clinical Pharmacology, Karolinska Institute, Karolinska University Hospital Huddinge, 14186 Stockholm, Sweden 